\title{
Article
}

\section{Electrochemical Dissolution of Iridium and Iridium Oxide Par- ticles in Acidic Media: Transmission Electron Microscopy, Electrochemical Flow Cell Coupled to Inductively Coupled Plasma Mass Spectrometry and X-ray Absorption Spectros-copy Study}

Primož Jovanovi\#, Nejc Hodnik, Francisco Ruiz-Zepeda, Iztok Arcon, Barbara Jozinovi\#, Milena

Zorko, Marjan Bele, Martin Šala, Vid Simon Šelih, Samo B. Hocevar, and Miran Gaberscek

J. Am. Chem. Soc., Just Accepted Manuscript • DOI: 10.1021/jacs.7b08071 • Publication Date (Web): 15 Aug 2017

Downloaded from http://pubs.acs.org on August 23, 2017

\section{Just Accepted}

"Just Accepted" manuscripts have been peer-reviewed and accepted for publication. They are posted online prior to technical editing, formatting for publication and author proofing. The American Chemical Society provides "Just Accepted" as a free service to the research community to expedite the dissemination of scientific material as soon as possible after acceptance. "Just Accepted" manuscripts appear in full in PDF format accompanied by an HTML abstract. "Just Accepted" manuscripts have been fully peer reviewed, but should not be considered the official version of record. They are accessible to all readers and citable by the Digital Object Identifier (DOI®). "Just Accepted" is an optional service offered to authors. Therefore, the "Just Accepted" Web site may not include all articles that will be published in the journal. After a manuscript is technically edited and formatted, it will be removed from the "Just Accepted" Web site and published as an ASAP article. Note that technical editing may introduce minor changes to the manuscript text and/or graphics which could affect content, and all legal disclaimers and ethical guidelines that apply to the journal pertain. ACS cannot be held responsible for errors or consequences arising from the use of information contained in these "Just Accepted" manuscripts. 
Electrochemical Dissolution of Iridium and Iridium Oxide Particles in Acidic Media: Transmission Electron Microscopy, Electrochemical Flow Cell Coupled to Inductively Coupled Plasma Mass Spectrometry and X-ray Absorption Spectroscopy Study

\author{
Primož Jovanovič* ${ }^{\dagger}$, Nejc Hodnik ${ }^{*}$, Francisco Ruiz-Zepeda ${ }^{\dagger}$, Iztok Arčon ${ }^{\nabla,}$ "I, Barbara Jozinović ${ }^{\dagger}$,

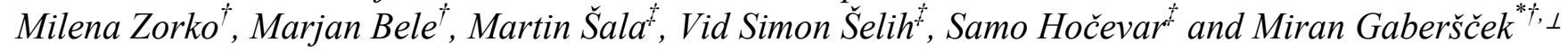 \\ †Department of Materials Chemistry, National Institute of Chemistry Hajdrihova 19, 1000 Ljubljana, \\ Slovenia \\ $\S$ Department of Catalysis and Chemical reaction Engineering, National Institute of Chemistry Hajdri- \\ hova 19, 1000 Ljubljana, Slovenia \\ DUniversity of Nova Gorica, Vipavska 13, Nova Gorica, Slovenia \\ /IJozef Stefan Institute, Jamova 39, Ljubljana, Slovenia \\ $\neq$ Department of Analytical Chemistry, National Institute of Chemistry, Hajdrihova 19, 1000 Ljubljana, \\ Slovenia \\ $\perp$ Faculty of Chemistry and Chemical Technology, University of Ljubljana, Večna pot 113, SI-1000 \\ Ljubljana, Slovenia
}

\begin{abstract}
Iridium based particles as the most promising proton exchange membrane electrolyser electrocatalysts were investigated by transmission electron microscopy (TEM), and by coupling of electrochemical flow cell (EFC) with online inductively coupled plasma mass spectrometer (ICP-MS). Additionally, a thin-film rotating disc electrode (RDE), an identical location transmission and scanning electron microscopy (IL-TEM and IL-SEM) as well as an X-ray absorption spectroscopy (XAS) studies have been performed. Extremely sensitive online time-and potential-resolved electrochemical dissolution profiles revealed that iridium particles dissolved already well below oxygen evolution reaction (OER) potentials, presumably induced by iridium surface oxidation and reduction processes, also referred to as transient dissolution. Overall, thermally prepared rutile type $\operatorname{IrO}_{2}$ particles $\left(\mathrm{T}\right.$-IrO $\left.\mathrm{I}_{2}\right)$ are substantially more stable and less active in comparison to as prepared metallic (A-Ir) and electrochemically pretreated (E-Ir) analogues. Interestingly, under OER relevant conditions E-Ir particles exhibit superior stability and activity owing to the altered corrosion mechanism where the formation of unstable $\operatorname{Ir}(>\mathrm{IV})$ species is hindered. Due to the enhanced and lasting OER performance, electrochemically pre-oxidized E-Ir particles may be considered as the electrocatalyst of choice for an improved low temperature electrochemical hydrogen production device, namely a proton exchange membrane electrolyser.
\end{abstract}

INTRODUCTION Iridium based materials are used for many applications among which the most important are electrochemistry and electrocatalysis ${ }^{1}$. Their implementation covers a broad range spreading from photoelectrochemistry ${ }^{2}$, supercapacitors $^{3}$, batteries ${ }^{4}$, electrocatalysis ${ }^{5-7}$, medicine ${ }^{8-10}$. In the field of sustainable energy infrastructure iridium materials are showing promising results in terms of both activity and stability. Extensive iridium usage has been reported in Polymer Electrolyte Membrane (PEM) water electrolysers ${ }^{6}$. The latter combined with renewable electric power generation technologies, such as solar, hydro, or wind power plants, is expected to become one of the pillars of sustainable energy utilization through electricity to hydrogen conversion and storage $^{7,11}$. Due to misfit between supply and demand, oscillations of excess electricity will need to be converted and stored in a form of chemicals such as, for example, hydrogen fuel as part of a solar refinery ${ }^{12}$.

Iridium materials have proven to be an efficient PEM anode electrocatalyst for oxygen evolution reaction (OER) ${ }^{13-15}$. In general, OER represents a bottleneck for efficient electrocatalytic water splitting due to its high overpotential as opposed to its counter reaction - the cathodic hydrogen evolution reaction (HER). In comparison to other OER catalysts, iridium based materials show superior corrosion stability that compensates for their lower activity when compared to the most active $\mathrm{Ru}$ based analogues ${ }^{14,16,17}$. Employment of iridium has also been introduced to PEM fuel cells and regenerative PEM fuel cells where its corrosion protection ability at high potential excursions has been reported ${ }^{6,18}$. It needs to be noted that in alkaline electrolyzers transition metals $(\mathrm{Ni}, \mathrm{Co})$ based materials are the-state-of-the-art electrocatalysts - rather than Ir or Ru based. As regards Pt, it is known to be a poor OER catalyst ${ }^{14}$.

In general it is accepted that the stability and activity are in inverse relationship ${ }^{19}$. For Ir based materials, stability is increasing with crystallinity of the oxides $\left(\mathrm{IrO}_{\mathrm{x}}\right)$. However, also reverse trends have been observed for OER activity ${ }^{15,16}$. Recent detailed mechanistic studies of the activity of Ir based catalyst have indicated that reactive electrophilic $\mathrm{O}^{\mathrm{I}-}$ oxygen species form in a mixed-valent iridium ${ }^{\text {II//VV }}$ hydrated amorphous oxyhydroxides $\left(\mathrm{IrO}_{\mathrm{x}}\right)$ during the OER which could be responsible for the higher activity in comparison to crystalline analogues ${ }^{20}$. The recent report of unexpectedly high stability 
of nanostructured iridium oxide has indicated that stability and activity are not necessarily in a trade-off relationship 16,21,22. Interestingly, the concepts for tuning the catalyst activity and stability used in PEM electrolyzers are in many ways similar to those found in PEMFC research. An example is alloying with transition metals. In the case of $\mathrm{Ru}$ and Ir catalysts such alloying showed an improved OER activity ${ }^{6,21,23-25}$. Furthermore, core-shell configuration was reported to boost the OER activity of $\mathrm{Ir}$ based composites where $\mathrm{IrO}_{\mathrm{x}}$ was in the shell and $\mathrm{NiOH}$ in the core ${ }^{26,27}$. The activity improvement was ascribed to the electronic interaction of the non-noble core (ligand and/or strain effect) ${ }^{28,29}$. The morphology of iridium surface was found to have an important impact on activity and durability; the effect was demonstrated for oxide-supported iridium nanodendrites ${ }^{30}$ and $\mathrm{IrO}_{2}$ nanotube arrays ${ }^{31}$. As a whole, Ir based nanoparticles still represent a state-of-the-art OER electrocatalyst in acidic media ${ }^{32}$, therefore a deeper understanding of their corrosion behavior is of high importance. Furthermore, new insights in corrosion mechanisms, such as the process of transient dissolution, have been found potentially useful for innovative recycling of noble metals ${ }^{33}$.

In the present contribution the potentiodynamically induced dissolution of iridium based particles is addressed. In our recent work a combined analytical approach using a thin film rotating disc electrode (TF-RDE), identical location scanning electron microscopy (IL-SEM) and a high sensitivity electrochemical flow cell coupled to an inductively coupled plasma mass spectrometer (EFC ICP-MS) has been successfully utilized for the case of $\mathrm{Ru}$ based nanoparticles ${ }^{34}$. In the present study an analogous approach, but additionally upgraded with identical location transmission electron microscopy and X-ray absorption spectroscopy (XAS), is extended on iridium based particles where substantially different corrosion behavior is generally observed. In order to get a wider picture, three differently prepared Ir-based particles, however with identical particle size distribution, are studied: (i) as prepared pure iridium (A-Ir; Ir Black), (ii) electrochemically oxidized iridium (E-Ir) and (iii) thermally prepared $\mathrm{IrO}_{2}\left(\mathrm{~T}-\mathrm{IrO}_{2}\right)$. The typical potential window is between 0.05 and $1.6 \mathrm{~V}$ vs RHE under potentiodynamic conditions in acidic media. Several new insights into the nature of Ir corrosion under various conditions of interest are reported and commented with respect to its impact on OER activity.

EXPERIMENTAL SECTION First $\mathrm{IrO}_{2}$ was prepared by dissolving $0.3 \mathrm{mmol}$ of Ir salt (iridium chloride; Acros Organics, Geel, Belgium) and $0.3 \mathrm{mmol}$ citric acid (Sigma-Aldrich, USA) in $5 \mathrm{ml}$ of water. The solution was mixed at $50^{\circ} \mathrm{C}$ till evaporation. Then the mixture was thermally treated at $500^{\circ} \mathrm{C}$ in air atmosphere for $5 \mathrm{~h}$. At this point nearly all of the carbon was burned away, as can be seen from TEM images (see Results and Discussion section). Pure metallic A-Ir was prepared by reducing the thermally prepared $\mathrm{T}-\mathrm{IrO}_{2}$ in a furnace at 500 ${ }^{\circ} \mathrm{C}$ under reductive hydrogen atmosphere $\left(5 \% \mathrm{H}_{2}\right.$ in $\left.\mathrm{Ar}\right)$ for $5 \mathrm{~h}$. Ir-A can be considered similar to the wider known Ir-Black samples that are traditionally used in PEM electrolysers and can be purchased as industrial benchmarks from various companies. E-Ir was prepared by electrochemical irreversible oxiditation of the Ir-A sample with 200 potential cycles between 0.05 and $1.2 \mathrm{~V}$ with a scan rate $300 \mathrm{mVs}^{-1}$. Therefore the particle size distribution (PSD) is more or less the same for all samples. We note that the PSD of $\mathrm{T}-\mathrm{IrO}_{2}$ is systematically larger (a few $\mathrm{nm}$ ) due to the presence of oxygen in the oxide.
The setup in which an electrochemical flow cell is coupled with ICP-MS has already been introduced in our previous publications ${ }^{34-39}$. Shortly, a commercial BASi electrochemical flow cell (Cross-Flow Cell Kit MW-5052) with a homemade silicon gasket of a $1 \mathrm{~mm}$ thickness was coupled with an Agilent 7500ce ICP-MS instrument (Agilent Technologies, Palo Alto, USA) equipped with a MicroMist glass concentric nebulizer and a Peltiercooled Scott-type double-pass quartz spray chamber. A forward radio frequency power of $1500 \mathrm{~W}$ was used with Ar gas flows: carrier $0.85 \mathrm{~L} / \mathrm{min}$, makeup 0.28 $\mathrm{L} / \mathrm{min}$, plasma $1 \mathrm{~L} / \mathrm{min}$, and cooling $15 \mathrm{~L} / \mathrm{min}$. $0.1 \mathrm{~mol} / \mathrm{L}$ $\mathrm{HClO}_{4}$ (Aldrich 70\%, 99.999\% trace metals basis) acid was used as the electrolyte carrier medium. Solutions were pumped at $263 \mu \mathrm{L} / \mathrm{min}$ using a syringe pump (WPI sp100i). Catalyst thin film preparation was the same as for the thin film rotating disc electrode (TF-RDE) measurements. The catalyst powder was dispersed in Milli-Q water resulting in a concentration of $1 \mathrm{mg} / \mathrm{mL}$ for all samples investigated. Suspension was cast dropped over a glassy carbon electrode and stabilized by a 5 $\mu \mathrm{L}$ of Nafion diluted by isopropanol (1/50). For all investigated samples, the deposited amount was $5 \mu \mathrm{g}$. The typical experimental procedure consisted of consecutive cycling from 0.05 $\mathrm{V}$ to different upper potential limits starting at $0.9 \mathrm{~V}$ and increasing by $0.1 \mathrm{~V}$ till $1.6 \mathrm{~V}$ vs. RHE. During each potential excursion, 3 cycles were recorded. We note that during potential cycling an extremely small amount of sample is dissolved (e.g. even in the case of the highest upper potential limit, 1.6 $\mathrm{V}$, only around $0.007 \%$ of monolayer of sample dissolves). Thus performing experiments by proceeding from milder to harsher conditions should give quite reliable trends, even if the same sample is used at all conditions. Details about the TFRDE and IL-SEM experimental procedures have already been given in our previous papers ${ }^{40-42}$. The electrochemical TFRDE degradation test included 10000 cycles between 1 to 1.6 $\mathrm{V}$ vs. SCE with a scan rate $1 \mathrm{~V} / \mathrm{s}$. OER activity was determined in a slow cyclovoltammetric experiment $(10 \mathrm{mV} / \mathrm{s}$ with IR compensation) in the same potential window.

Transmission Electron Microscopy (TEM) and aberration corrected scanning-TEM (AC-STEM) images, along with Energy Dispersive X-ray Spectroscopy (EDX) and Electron Energy Loss Spectroscopy (EELS), were acquired using a probe Cs-corrected with a cold-field-emission-gun JEOL ARM $200 \mathrm{CF}$ microscope, operated at $200 \mathrm{kV}$ and $80 \mathrm{kV}$, equipped with a SSD Jeol EDX spectrometer and a GIF Quantum spectrometer. Samples were prepared by the drop casting method on lacey $\mathrm{Cu}$ grids. Details about the IL-TEM procedure can be found in our recent paper ${ }^{43}$.

X-ray absorption near edge structure (XANES) and near edge X-ray absorption fine structure (EXAFS) experiments were performed in combination with ex situ electrochemical treatment of Ir analogues. Similar concept has been employed before for investigating Ir OER catalyst with X-ray photoemission spectroscopy (XPS) and NEXAFS in a quasi in situ mode ${ }^{20}$. For this purpose an electrochemical cell consisted of screen-printed electrodes with carbon working $(\mathrm{d}=4 \mathrm{~mm})$ and counter electrode, and silver quasi-reference electrode (DropSens, Oviedo) were employed. 0.1 $\mathrm{M} \mathrm{HClO}_{4}$ was chosen as the working electrolyte. Prior to electrochemical experiment the potential of the reference electrode towards the RHE was determined by measuring the open circuit potential under $\mathrm{H}_{2}$ atmosphere. Electrochemical treatment was conducted under potentiostatic regime. In the case of E-Ir analogue 200 activation cycles were performed (analogously as described above) 
before potentiostatic treatment. After each potential sequence the electrochemical cell, still covered with a thin layer of liquid electrolyte, was transferred to X-ray absorption chamber (for a detailed description see Supporting Info, section "Quasi in situ electrochemical XANES and EXAFS study").

Structure and morphology of samples. Structural characterization of A-Ir and $\mathrm{T}$ - $\mathrm{IrO}_{2}$ was performed using X-ray diffraction (Fig. 1). In the case of E-Ir diffractograms could not be obtained due to the very small amount of sample collected on the $5 \mathrm{~mm}$ electrode during potential cycling. However, all three materials could be examined using TEM electron diffraction analysis (Fig. 2) where also the precise crystal structure of nanoparticles is detected. In general, both methods consistently confirmed the metallic nature of sample A-Ir (Fm-3m) and the expected rutile structure $\left(\mathrm{P}_{2} / \mathrm{m} \mathrm{n} \mathrm{m}\right)$ of T-IrO $\mathrm{I}_{2}$.

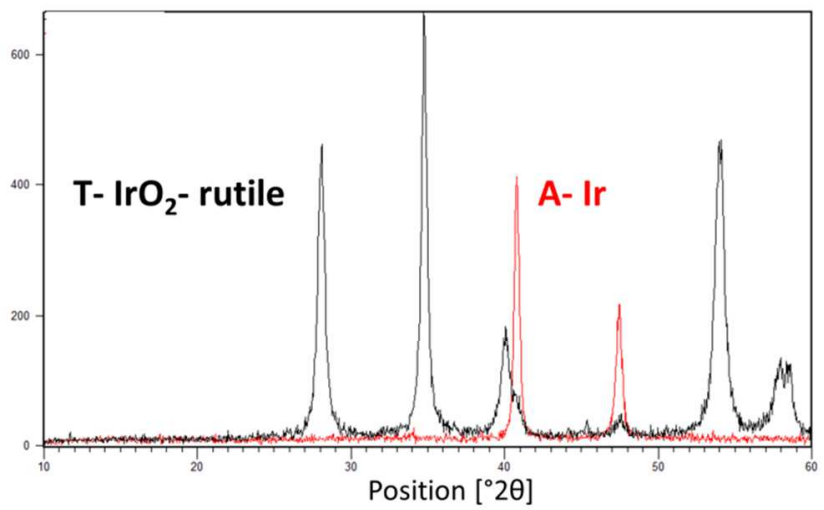

Figure 1. Structural characterization XRD pattern of investigated analogues: A-Ir and T-IrO $\mathrm{I}_{2}$.

In the case E-Ir analogue, interestingly, mainly metallic Ir features were identified (Fig. 2c). Further discussion of this finding can be found below. In all analogues, the TEM imaging (Fig. 2) shows a comparable but rather wide particle size distribution.

(a)

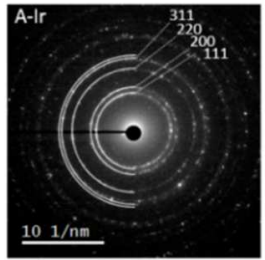

(b)

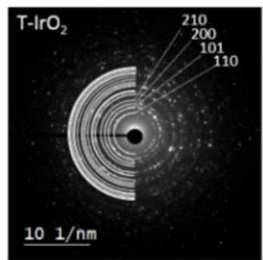

(c)
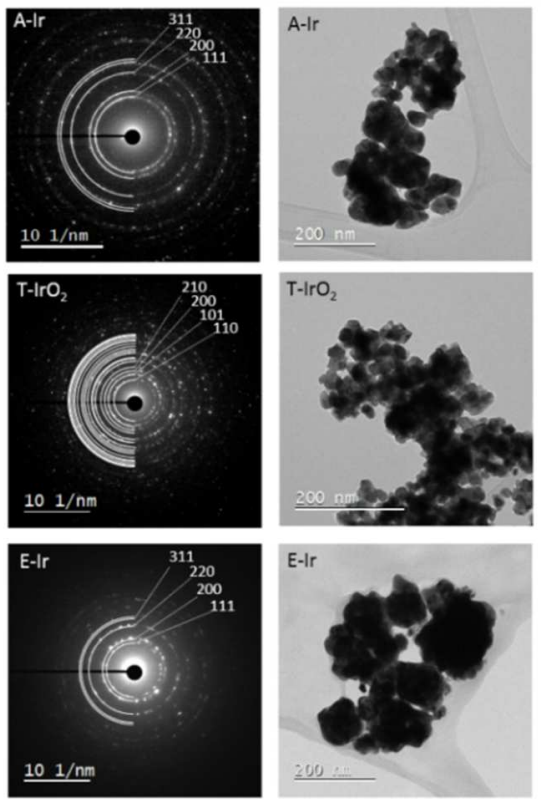

Figure 2. Electron diffraction and transmission electron microscopy imaging of particles. (a) A-Ir, (b) $\mathrm{T}-\mathrm{IrO}_{2}$ and (c) E-Ir.

\section{RESULTS AND DISCUSSION}

\section{Transmission Electron Microscopy}

A-Ir analogue:

A careful observation of A-Ir reveals the presence of pores (Fig. 3a, 3d, S1) or voids which, presumably, are due to sintering of nanoparticles in the annealing steps. Chemical mapping revealed the presence of carbon and oxygen signals (Fig. S2). We note that the residual carbon comes from the synthesis procedure whereas oxygen signals are attributed to formation of surface oxides during air exposure before sample had been characterized ${ }^{44}$. The morphology corresponds to an aggregate of crystallites with a rough surface. Furthermore, the presence of grain boundaries, twin defects and high indexed planes are observed in most of the analyzed particles (Fig. 3b, 3d, S3). Additionally, one can observe the presence of small nanoparticles embedded in carbon. Their size extends from 1 to $5 \mathrm{~nm}$ and they are mostly located at the surface of larger crystallites (Fig. 3c, 4). It is worth mentioning that some of the small nanoparticles also show small voids.
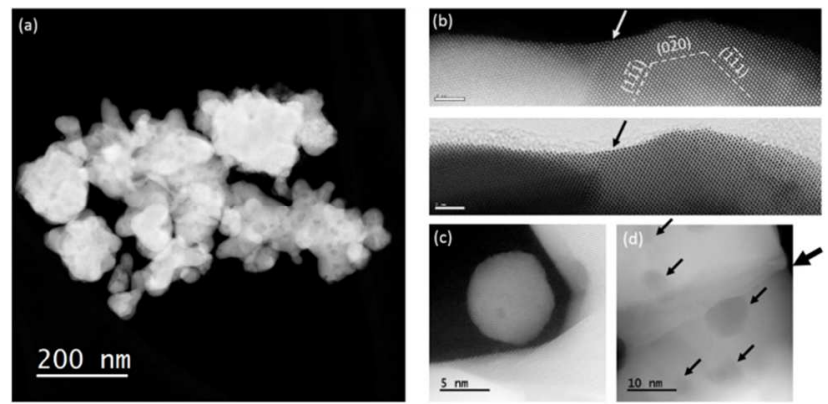

Figure 3. (a) STEM-HAADF image of A-Ir particles with a porous and rough morphology. (b) HAADF and BF images showing a twin defect and atomic steps at the surface. (c) A smaller Ir particle with round shape at the surface of a bigger Ir particle. (d) Detail of a grain boundary between two Ir crystallites and pores or voids of $2 \mathrm{~nm}$ to $10 \mathrm{~nm}$.
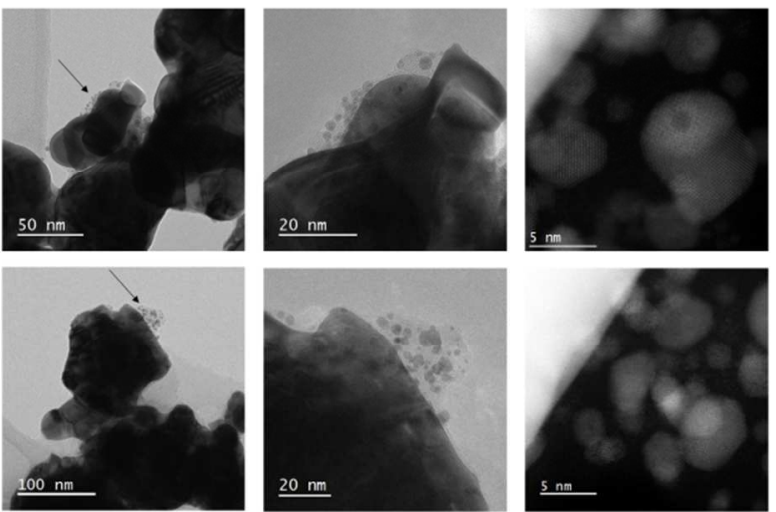

Figure 4. TEM and STEM-ADF images of A-Ir crystallites with 2-8 $\mathrm{nm}$ Ir nanoparticles embebed in carbon at the surface.

E-Ir analogue: First we note again that E-Ir is in fact A-Ir that was subjected to additional electrochemical activation cycles prior to characterization. In order to inspect the effects of electrochemical pretreatment as clearly as possible, identical location transmission microscopy (IL-TEM) analysis was performed before and after the treatment (see Fig. S15). Remarkably, the biggest difference is the presence of single atoms and clusters in E-Ir located within the carbon-based amorphous film or Nafion (IL-TEM Fig. 5, see also S9). This was confirmed by image simulation and EELS spectra (Fig. 
$\mathrm{S} 10$ and S11). The presence of Ir single atoms could be due to electrochemical dissolution of small particles induced by formation of surface Ir oxide during the electrochemical pretreatment. Additionally, Ir oxide is prone to decomposition induced by the reductive nature of electron beam used during TEM analysis (see Scheme S12). Dissolution of small particles is also in line with a general TEM inspection where small particles are not observed that often (Fig. S5, S4). Therefore, the absence of small particles should be ascribed to their removal through the electrochemical dissolution during the activation pretreatment. Apart from that, no significant structural differences are found before (A-Ir analogue) and after (EIr analogue) electrochemical pretreatment. Importantly, also in the case of E-Ir high index facets and steps are clearly still present (Fig. S5d, S6). The expected presence of irreversibly grown iridium oxides as a result of electrochemical pretreatment in this analogue could not be directly confirmed ${ }^{32,45}$. This is ascribed to: i) the presence of residual carbon which may also contain oxygen (see chemical mapping in Fig. S7) ii) presence of Nafion (also containing oxygen) indicated by detection of flourine (Fig. S8). Nafion was used as a binder to prevent detachment from the electrode during the electrochemical preparation of E-Ir analogue and is compared to the residual synthesis carbon evenly covering the surface of particles; iii) too low oxidative potentials during electrochemical pretreatment to form enough oxide or (iv) decomposition of $\mathrm{Ir}$ oxides under electron beam as mentioned above.

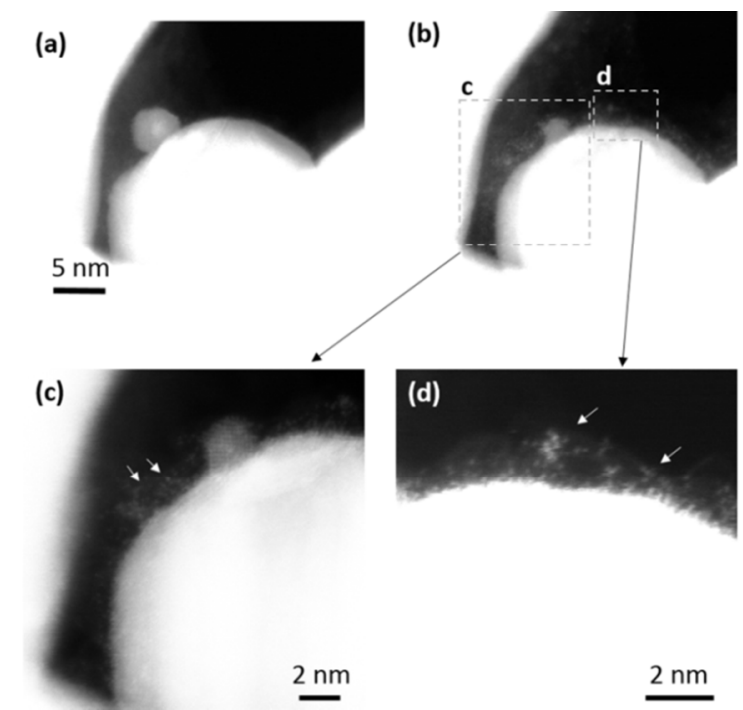

Figure 5. IL-(S)TEM-HAADF images of (a) before and (b) after EC of an Ir particle. (c) and (d) are close ups regions of (b) displaying single atoms at the surface of the Ir particle, marked with arrows.

${\underline{\mathrm{T}}-\mathrm{IrO}_{2}}_{2}$ analogue: As mentioned, XRD (Fig. 1) showed that thermal oxidation, during which the $\mathrm{T}-\mathrm{IrO}_{2}$ analogue was prepared, changed completely the crystal structure if compared to the A-Ir material (Fig. 6a). Electron diffraction, in turn, reveals that in the case of $\mathrm{T}-\mathrm{IrO}_{2}$ a combination of rutile crystal structure and pure Ir metallic phase is present, where the rutile phase is predominant (Fig. 1, 2). It is clearly detected that the two phases form a core-shell type of particles, where $\mathrm{IrO}_{2}$ forms a shell sorounding an $\mathrm{Ir}$ core (Fig. 6b, 6c). The core-shell configuration is additionally confirmed by EDX chemical mapping (Fig. S13). The morphology of $\mathrm{T}-\mathrm{IrO}_{2}$ analogue is much more diverse in comparison to the A-Ir and E-Ir analogues (Fig. 6a). Apart from rounded shaped particles, also needles and cuboids are seen (Fig. S13), which are common morphologies of thermally grown oxides ${ }^{15,46}$.

Summarizing the results of the compositional, structural and morphological studies presented above, one may find several important similarities as well as differences between the three samples that may have important influence on their electrochemical behavior: (i) particle size distrubutions is similar in all Ir analogues, (ii) in the case of E-Ir smaller particles are absent - probably due to their dissolution in electrochemical pretreatment, however Ir single atoms are seen inside the Nafion coating (iii) the $\mathrm{T}-\mathrm{IrO}_{2}$ analogue consists of core-shell particles where $\mathrm{IrO}_{2}$ forms a shell surrounding an Ir core (Fig. $6 \mathrm{c})$; generally, in this sample the morphology is much richer in features (Fig. 6a). (a)

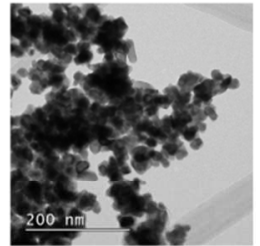

(b)

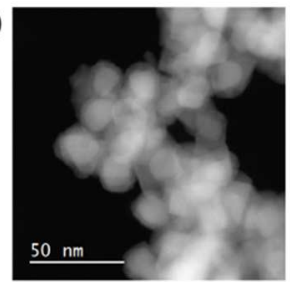

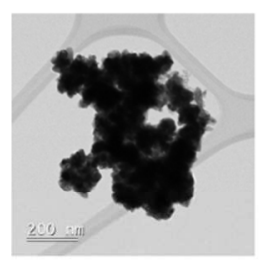

(c)

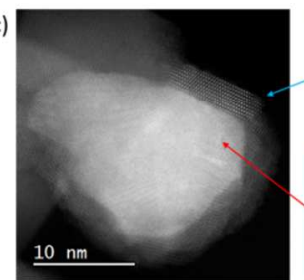

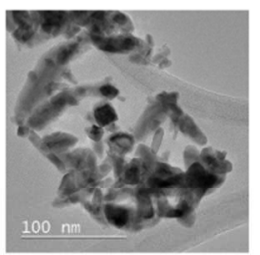

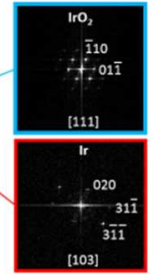

Figure 6. (a) TEM images of $\mathrm{T}-\mathrm{Ir}_{2} \mathrm{O}$ nanoparticles with different morphologies. (b) STEM-HAADF image of core-shell $\mathrm{Ir}$ and $\mathrm{IrO}_{2}$ nanoparticles agglomerate. (c) STEM-HAADF image close-up of Ir and $\mathrm{IrO}_{2}$ nanoparticle core-shell with Fast Fourier Transform from $\mathrm{Ir}$ and $\mathrm{IrO}_{2}$.

Dissolution of as prepared (A-Ir) and electrochemically oxidized (E-Ir) iridium particles On-line electrochemical flow cell ICP-MS experiments typically revealed two characteristic features in Ir dissolution profiles for all three samples (Figs. 7-10). These corrosion features are assigned to the transient dissolution phenomena triggered by transitions between different Ir oxidation states, as described by Equations 1-6 ${ }^{47}$ :

Electrochemical dissolution due to reduction of irreversible oxide $^{47}$ :

$\mathrm{IrO}_{\mathrm{x}}+2 \mathrm{xH}^{+}+2 \mathrm{xe}^{-} \rightarrow \mathrm{Ir}^{\mathrm{y}+}+\mathrm{xH}_{2} \mathrm{O}$

(The potential of this reaction (E) is not defined in Pourbaix diagrams).

Electrochemical dissolution due to direct dissolution:

$\mathrm{Ir} \rightarrow \mathrm{Ir}^{+3}+3 \mathrm{e}^{-}$

$\left(E=1.156 \mathrm{~V}+0.0197 \log \left[\mathrm{Ir}^{3+}\right]\right)$

Electrochemical dissolution due to reversible formation of surface oxide:

$$
\begin{aligned}
& 2 \mathrm{Ir}+\underset{(3)}{3 \mathrm{H}_{2} \mathrm{O}} \rightarrow \mathrm{Ir}_{2} \mathrm{O}_{3}+6 \mathrm{H}^{+}+6 \mathrm{e}^{-} \\
& (\mathrm{E}=0.926 \mathrm{~V}-0.0591 \mathrm{pH})
\end{aligned}
$$


Electrochemical dissolution due to reversible formation of surface oxide:

$$
\begin{aligned}
& \mathrm{Ir}+2 \mathrm{H}_{2} \mathrm{O} \rightarrow \mathrm{IrO}_{2}+4 \mathrm{H}^{+}+4 \mathrm{e}^{-} \\
& (\mathrm{E}=0.926 \mathrm{~V}-0.0591 \mathrm{pH}) \\
& \mathrm{Ir}_{2} \mathrm{O}_{3}+\mathrm{H}_{2} \mathrm{O} \rightarrow 2 \mathrm{IrO}_{2}+2 \mathrm{H}^{+}+2 \mathrm{e}^{-} \\
& (\mathrm{E}=0.926 \mathrm{~V}-0.0591 \mathrm{pH}) \\
& \mathrm{Ir}_{2} \mathrm{O}_{3}+5 \mathrm{H}_{2} \mathrm{O} \rightarrow 2 \mathrm{IrO}_{4}^{2-}+10 \mathrm{H}^{+}+6 \mathrm{e}^{-} \\
& \left(E=1.680 \mathrm{~V}-0.0985 \log \mathrm{pH}+0.0197 \log \left[\operatorname{IrO} \mathbf{4}^{-2}\right]\right)
\end{aligned}
$$

For A-Ir, in the cathodic (reductive) potential sweep, the dissolution occurs at about $0.09 \mathrm{~V}$ vs RHE (peak 1 in Fig. 7a, red graph). This corresponds to the electrochemical cathodic dissolution as a result of reduction of $\mathrm{IrO}_{\mathrm{x}}$ species (Equation 1). Such transient degradation phenomena have recently been well documented in the literature reports on various noble metals and can generally be ascribed to the highly disruptive process of removal of oxygen from the crystal structure of surface oxides ${ }^{34,38,48-50}$. The presence of iridium oxide, which is hardly visible in TEM analysis, can either result from exposure to air ${ }^{44}$ (in the case of A-Ir (Fig. S2)) or from the precycling step in E-Ir (Fig. S7). In the case of E-Ir, apart from the cathodic dissolution an anodic counterpart can also be clearly visible (peak 2 in Fig. 7a, blue curve). The anodic dissolution takes place already at $0.9 \mathrm{~V}$ vs RHE (Fig. 7a). This indicates the formation of iridium oxide with higher oxidation states ${ }^{34,45,48,51}$ as described by Equations 3-5 ${ }^{47}$. By further increasing the upper potential to values above $0.9 \mathrm{~V}$ vs RHE, transient redox processes intensify the anodic dissolution. For example, when cycling till $1 \mathrm{~V}$ (Fig. $7 \mathrm{~b}$ ) the rate of direct electrochemical dissolution due to oxidation of Ir to $\operatorname{Ir}(\mathrm{III})$ (Equation 2) is accelerated, whereas upon further increase of potential to values above $1.4 \mathrm{~V}$ vs RHE, where oxygen evolution reaction (OER) occurs, the oxide mediated dissolution contributes to overall iridium corrosion (Fig. 8d). It has been reported that surface oxides are participating in OER ${ }^{52}$. Simultaneously, formation of soluble $\mathrm{IrO}_{4}^{-2}$ is taking place (Equation 6) leading to increased dissolution of Ir based catalysts 22,48,51,53-55
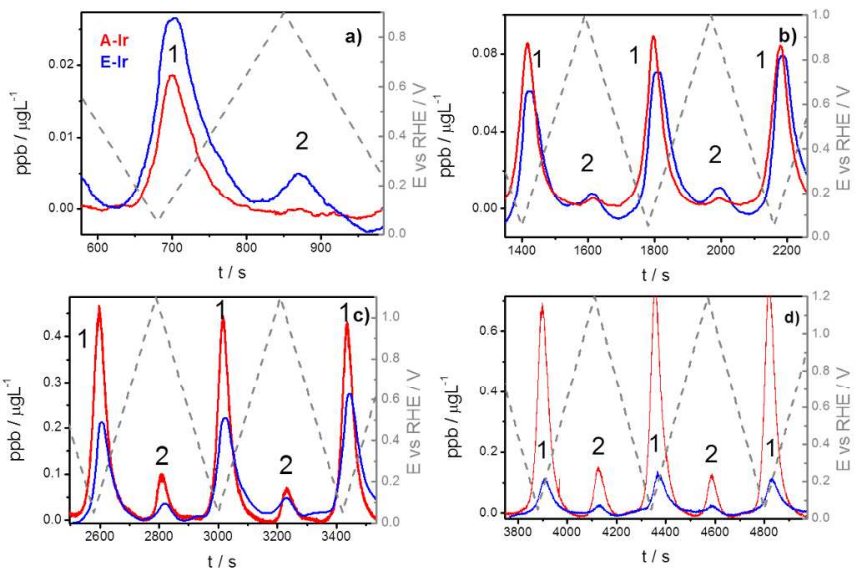

Figure 7. Potentially resolved dissolution profiles A-Ir (red) and E-Ir (blue) during cycles till upper potential limit of a) $0.9 \mathrm{~V}, \mathrm{~b}$ ) 1 $\mathrm{V}, \mathrm{c}) 1.1 \mathrm{~V}$ and d) $1.2 \mathrm{~V}$ vs RHE.
Comparison of dissolution signals of E-Ir and A-Ir reveals that the latter is substantially less stable (see various conditions in Figs. 7 and 8). This is in line with the known general trend in noble metal catalysts where the less active metal or metal oxide has been found to be less prone to corrosion 16,19,34. Since E-Ir was prepared by electrochemical cycling (200 CVs from 0.05 to $1.2 \mathrm{~V}$ with $300 \mathrm{mVs}^{-1}$ ), its surface is made of amorphous oxides, also referred to as hydrous oxides, which were shown to be less active than pure metal ${ }^{15,22,56}$. The surface of the A-Ir analogue is probably composed of a much smaller amount of Ir oxide the formation of which was supposedly induced by exposure to air. It is assumed that any disturbance of the thin oxidized surface results in exposure of Ir atoms underneath, which are typically more prone to dissolution ${ }^{34}$. Consequently, both dissolution events (peak 1 and 2) are increased in comparison to E-Ir where the surface is passivated with possibly much thicker and/or more homogeneous oxide layer (Fig. 7c,d and Fig. 8). However, a detailed investigation of dissolution profiles for the two analogues reveals a reversed trend during first two potential sequences, namely till the upper potential limit 0.9 and $1 \mathrm{~V}$ vs. RHE (Fig. 7a,b) where sample A-Ir exhibits a less intense dissolution. The difference between A-Ir and E-Ir is especially expressed in the anodic direction (Fig. 7a,b-peak 2). Most likely, such behavior is a consequence of the activation cycles by which E-Ir was prepared. This resulted in formation of $\operatorname{Ir}(\mathrm{III})$ and $\operatorname{Ir}(\mathrm{IV})$ species, presumably in a form of a mixture of hydrated and nonhydrated iridium oxides ${ }^{15,20,54,55,57-61}$. Corrosion due to transition of Ir (III) to $\operatorname{Ir}(\mathrm{IV})$ (Equation 5) is therefore expected for E-Ir ${ }^{54,55,62}$. In the case of $\mathrm{A}-\mathrm{Ir}$, no $\mathrm{Ir}_{2} \mathrm{O}_{3}$ oxide formation is expected, apart from a minor amount of oxide formed due to air exposure (Fig. S2) as evident from the cathodic dissolution peak 1 (Fig. 7 and Fig. 8). Furthermore, the surface area in EIr is much higher than in the case of A-Ir, hence more intense cathodic dissolution in the former case is monitored (Fig. 7a). We note here that the absence of $\operatorname{Ir}_{2} \mathrm{O}_{3}$ oxide in A-Ir is also the reason for barely visible anodic dissolution when cycling the material till the upper potential limit of $0.9 \mathrm{~V}$ (Fig. 8a). Based on suggested mechanisms (Eqs. 1-6), one would expect dissolution to occur at least due to three events: a reversible formation of (i) $\mathrm{Ir}_{2} \mathrm{O}_{3}$ and (ii) $\mathrm{IrO}_{2}$ from the non-oxidized form of Ir (Equations 3 and 4) and (iii) oxidation of $\mathrm{Ir}_{2} \mathrm{O}_{3}$ to $\mathrm{IrO}_{2}$ (Equation 5). Since A-Ir does not show anodic dissolution, it is clear that the first two events are not occurring. Thus we can assume that we do not have any bare Ir on the surface in the case of both analogues. Therefore the transition between oxides is again the only source of dissolution. Interestingly, this anodic corrosion event (peak 2 in Fig. 7a) occurs $100 \mathrm{mV}$ sooner if compared to the results by Cherevko et al. who, however, studied dissolution of an Ir disk ${ }^{54,55}$. This mismatch is an important difference that is attributed to the less stable nanoparticulate nature of our Ir sample - the so-called particle size effect.

As the upper potential limit is raised till 1.1 and $1.2 \mathrm{~V}$, respectively (Figs. 7c,d), A-Ir clearly shows a lower corrosion stability since both the anodic and the cathodic dissolution are enhanced. We presume that this is due to disturbance of the relatively thin air-induced oxide that exposes bare Ir.

An interesting phenomenon is detected when cycling till higher potential limits (1.5 and 1.6 V vs RHE, Figs. 8c,d). A close inspection of A-Ir cathodic dissolution shows that the peak due to reduction of irreversible oxide (Equation 1-peak 1) is 
lower when cycling till 1.6 than in the case of $1.5 \mathrm{~V}$. Furthermore, when cycling till $1.6 \mathrm{~V}$ (Fig. 8d) the anodic dissolution maximum (peak 2-Fig. 8d) is higher than its cathodic counterpart (peak 1). This kind of behavior is ascribed to formation of soluble $\mathrm{IrO}_{4}^{-2}$ (Equation 6) that is considered as an intermediate in OER ${ }^{56,63-65}$. The latter involves participation of surface oxides as well as formation of a less stable high oxidation state of $\mathrm{Ir}^{19,53}$. The surface therefore becomes oxide depleted, resulting in a more intensive dissolution under peak 2 in comparison to peak 1 (Fig. 8d). A similar trend was observed by Cherevko et al ${ }^{55}$ in the case of metallic iridium disks ${ }^{54}$ and electrochemically grown iridium oxide analogue. On the other hand, no such trend is noticed in the case of E-Ir, where peaks 1 and 2 are of same intensity and substantially lower in comparison to A-Ir (Fig. 8c,d). In E-Ir the surface presumably consists of amorphous, high surface area porous hydrous oxides ${ }^{45,55}$. This is in line with measured CVs, where higher capacitive currents were measured for the E-Ir (Fig. S18) ${ }^{34,66}$. However, even after severe long-term degradation (10 000 cycles till $1.6 \mathrm{~V}$ ) to high potentials, an identical location scanning microscope investigation (IL-SEM) could not reveal any noticeable morphological changes in E-Ir (Fig. 11). No significant changes, according to atomically resolved TEM and ILTEM images, are witnessed after the electrochemical preparation of E-Ir as well (Fig. 5 and Fig. S4-S6). It needs to be noted that the dissolution amounts are much lower (in the range of $0.0005 \%$ monolayer) compared to, for instance, platinum $(0.1 \%$ of monolayer $){ }^{40,67}$. Therefore unlike in $\mathrm{Pt}$ where morphological changes are visible, no such changes, on a larger scale, are expected for Ir. The only observed process is dissolution of small (below $5 \mathrm{~nm}$ ) Ir particles which resulted in formation of single atoms and some small clusters caught in the Nafion matrix (see also discussion in Transmission Electron Microscopy, Fig. 5, and Figs. S8-S10).
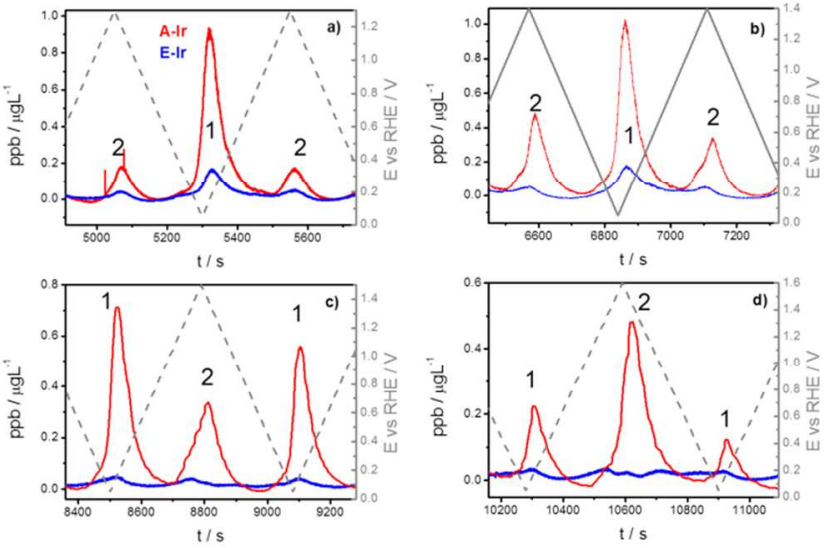

Figure 8. Potentially resolved dissolution profiles of A- Ir (red) and E-Ir (blue) during cycles till upper potential limit of a) $1.3 \mathrm{~V}$, b) $1.4 \mathrm{~V}$, c) $1.5 \mathrm{~V}$ and d) $1.6 \mathrm{~V}$ vs RHE.

The combined information obtained from IL-TEM and ILSEM together with Ir dissolution profiles indicates that the difference in behavior of A-Ir and E-Ir is primarily due to the different nature of initial oxide. Additionally, there are some differences due to absence of nanoparticles between 1 and 5 $\mathrm{nm}$ in E-Ir that could be the main source of the dissolution found in A-Ir. Interestingly, the lower onset potential of OER for E-Ir makes it a more active catalyst in comparison to A-Ir (Fig. S18) which is a deviation from the conventionally estab- lished relation of reversed activity-stability ${ }^{19}$. Nevertheless, our results are in agreement with several works reporting a good activity of hydrous iridium oxides ${ }^{15,21,58,65,68}$ as well as with the recently published literature on non-correlating nature of activity and stability of hydrous iridium oxides ${ }^{21,22,53}$. In the present paper, we are however providing new insights into corrosion behavior of the Ir-based particulate systems.

Corrosion of thermally prepared $\operatorname{IrO}_{2}\left(\mathrm{~T}-\mathrm{IrO}_{2}\right) \mathrm{A}$ dramatic increase in stability has been found for $\mathrm{T}-\mathrm{IrO}_{2}$, where two orders of magnitude lower concentrations (Fig. 9d) are monitored in comparison to A-Ir and E-Ir (Figs. 7, 8). This is in line with extensive literature reports on the superior stability of thermally prepared oxides due to the highly ordered rutile crystal structure and the presence of a lesser amount of defects $5,22,34,69$. Again, the dissolution profiles show a well pronounced cathodic dissolution at low potentials and an increasing anodic dissolution with increasing upper potential limit (Fig. 9). Interestingly, contrary to the trend in E-Ir and A-Ir (Fig. 7), $\mathrm{T}-\mathrm{IrO}_{2}$ shows quite comparable anodic and cathodic dissolution when cycling till the upper potential limit of $1.2 \mathrm{~V}$ (Fig. 9c,d). This is in accordance with the presence of $\mathrm{IrO}_{2}$ shell (Fig. 6c) and the fact that no bare Ir atoms are present on the surface. By further increasing the upper potential limit till $1.6 \mathrm{~V}$, peak 2 eventually becomes the dominant dissolution process (Fig. 10b-d). This is ascribed to disturbance of the rutile type of $\mathrm{IrO}_{2}$, formation of amorphous oxide and formation of $\operatorname{Ir}(>\mathrm{IV})$ compounds. Thus, an OER process through oxide decomposition dissolution takes place.
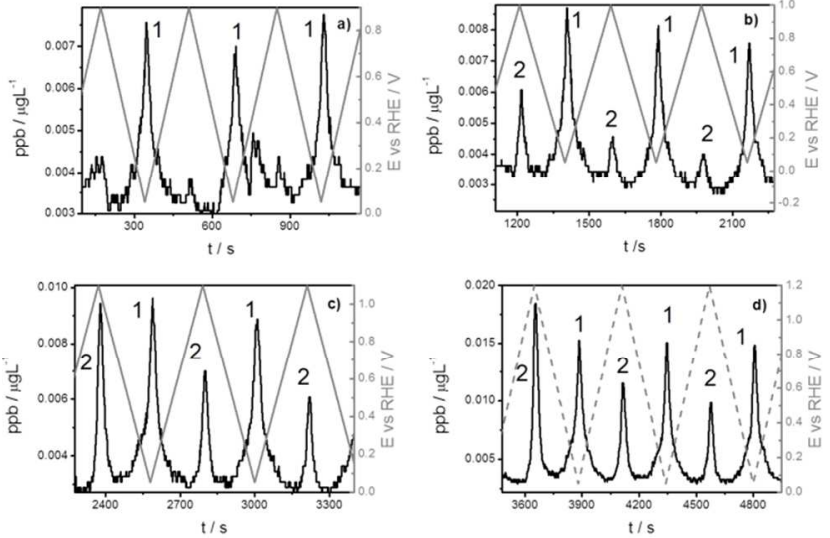

Figure 9. Potentially resolved dissolution profiles of $\mathrm{T}-\mathrm{IrO}_{2}$ during cycles till upper potential limit of a) $0.9 \mathrm{~V}$, b) $1.0 \mathrm{~V}$, c) $1.1 \mathrm{~V}$ and d) $1.2 \mathrm{~V}$ vs RHE.

Interestingly, in the OER potential region - when cycling till 1.5 V and 1.6 V vs RHE (Fig 10c,d) - the shapes of dissolution profiles for $\mathrm{T}-\mathrm{IrO}_{2}$ and E-Ir start to diverge. Namely, when cycling to the upper potential limit of $1.5 \mathrm{~V}$ vs RHE (Fig. $10 \mathrm{c}$ ), the onset of dissolution peak 2 in the case of $\mathrm{T}-\mathrm{IrO}_{2}$ occurs at substantially more positive potentials if compared to E-Ir. This indicates that more Ir(III) species (presumably $\mathrm{Ir}_{2} \mathrm{O}_{3}$ ) are present in the E-Ir analogue in comparison to T$\mathrm{IrO}_{2}$. This is consistent with recent mechanistic findings on hydrous Ir oxide where generation of Ir(III) was reported ${ }^{20,59-}$ ${ }^{61}$. This should be ascribed to OER mediated restructuring of the surface layer (in the previous cycle till $1.4 \mathrm{~V}$ ) where formation of Ir(III) has been documented and is more intense in the case of hydrous oxides 15,62,68 (see also the section on "Quasi in situ electrochemical XANES and EXAFS study" 
below). Additionally, the occurrence of several anodic dissolution maxima in the case of E-Ir - when cycling till $1.6 \mathrm{~V}$ (Fig. $10 \mathrm{~d})$ - indicates the differences in surface structure and/or composition between the analogues. In E-Ir the amorphous and porous surface oxide consists of a relatively higher number of Ir atoms that are exposed. In $\mathrm{T}-\mathrm{IrO}_{2}$, on the other hand, the more defined and compact oxide crystal structure contains a smaller portion of exposed/accessible Ir atoms, hence no early anodic dissolution onset is noticed (Fig. 10c,d). Peak multiplicity in the anodic and cathodic scans (labelled as 2c and $2 \mathrm{a}$ in Figs. 10c,d) of E-Ir proves that surface oxides are participating in OER and that they are converted to Ir or Ir(III) (presumably in the form of $\mathrm{Ir}_{2} \mathrm{O}_{3}$ ). Furthermore, the corrosion mechanism in the OER region seems to be somewhat different in E-Ir and $\mathrm{T}-\mathrm{IrO}_{2}$. The OER mechanism itself can be different in the case of these two analogues. In particular, the dissolution maximum 2 is suppressed in E-Ir if compared to $\mathrm{T}-\mathrm{IrO}_{2}$ (Fig. 10d). In the latter the redox transition of $\operatorname{Ir}(\mathrm{IV})$ to $\operatorname{Ir}(>\mathrm{IV})$ is the dominating dissolution mechanism. In the case of E-Ir, however, the dominating process is the transition of $\operatorname{Ir}(\mathrm{III})$ to Ir(IV) (peak 2a) and vice versa (peak 2c), which is in accordance with regeneration of $\operatorname{Ir}(\mathrm{III})$ during OER that has been reported in the case of hydrous oxides ${ }^{15,62,68}$. In this case, the cathodic dissolution corresponding to peak 1 consists of a prepeak (peak 1') which is ascribed to the more exposed/accessible Ir atoms that occur during reduction of less stable surface oxides that is easier to reduce compared to the thermal analogue. In the case of $\mathrm{T}-\mathrm{IrO}_{2}$ the formation of unstable $\operatorname{Ir}(>\mathrm{IV}){ }^{19}$ seems to be the dominating dissolution process when cycling above $1.4 \mathrm{~V}$ vs RHE (Fig. 10c,d). The discrepancy of the dissolution profiles of the two analogues in the OER region could suggest that the reaction mechanism is also different in case of the two analogues. It has been reported that the OER reaction mechanism depends on the type of metal surface. For instance, different metals have different equilibrium coverages with oxygen species, hence a different rate determining step in OER ${ }^{70}$. Furthermore, the amount and the nature of formed oxide (thickness) during OER is significantly different in case of different metals therefore dissolution rates are significantly different as well ${ }^{51,71}$. A similar explanation should be used in the case of E-Ir and $\mathrm{T}-\mathrm{IrO}_{2}$.
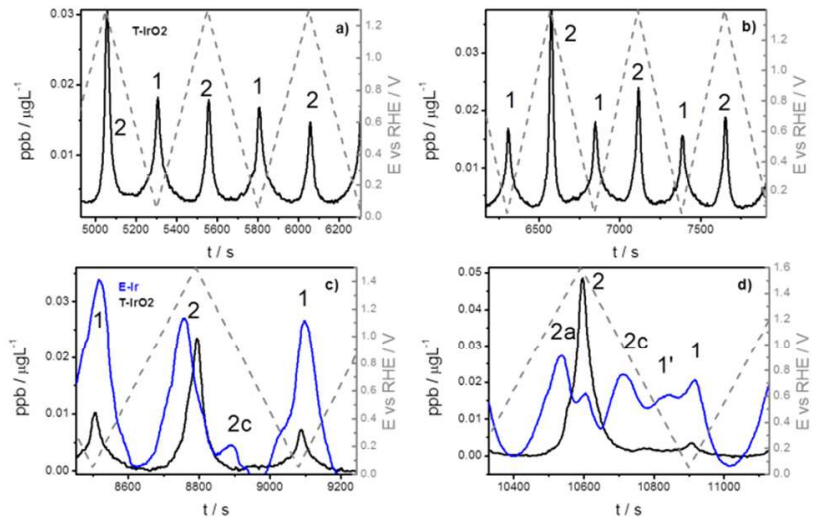

Figure 10. Potentially resolved dissolution profiles of $\mathrm{T}-\mathrm{IrO}_{2}$ (black) and E-Ir (blue) during cycles till upper potential limit of a) $1.3 \mathrm{~V}$, b) $1.4 \mathrm{~V}$, c) $1.5 \mathrm{~V}$ and d) $1.6 \mathrm{~V}$ vs RHE.

In the latter the oxide thickness is much bigger and so is the surface coverage (Fig. 6c). It is therefore expected that OER should have a different reaction pathway in the two analogues. For T- $\mathrm{IrO}_{2}$ the so called "oxide route" takes place which caus- es distortion and dissolution of the surface layer. In the case of E-Ir the oxide layer is much thinner, hence OER is proceeding through the so called "solution route" leading to smaller dissolution of the surface layer ${ }^{48}$. This fits well to the Ir dissolution trend in the OER region (peak 2 in Fig. 10d). Interestingly, no morphological differences between the analogues are visible during the long-term degradation experiment and a subsequent usage of identical location scanning electron microscopy (ILSEM) (Fig. 11). This is attributed to the low resolution under SEM, therefore formation of 3D hydrous oxide network cannot be noticed.

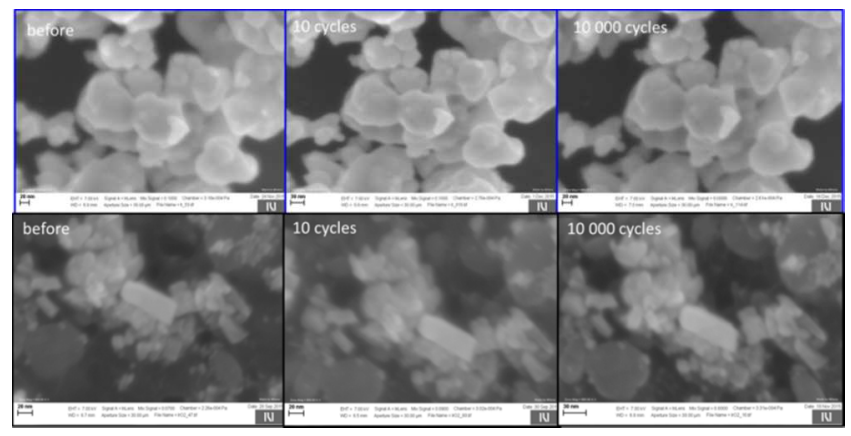

Figure 11. Identical location scanning electron microscopy (ILSEM) investigation: in blue boxes is E-Ir and in black boxes T$\mathrm{IrO}_{2}$.

\section{Quasi in situ electrochemical XANES and EXAFS study}

A combination of electrochemical treatment and subsequent XAS analysis was performed in order to further elucidate the main hypothesis from EFC-ICP MS study. Here we note that, in this particular experiment, A-Ir corresponds to the initial sample (hence also denoted as Ir/init) whereas all of the other samples correspond to a differently treated E-Ir sample. We start the discussion by explaining the impact of electrochemical activation cycles. The fit results of XANES spectra, listed in Table 1, indicate that electrochemical activation changes the oxidation state of Ir. Detailed XAS spectra fitting and interpretation are explained in Supporting Info (see section "Quasi in situ electrochemical XANES and EXAFS study"). Namely, during the activation cycles about 5\% Ir atoms that were initially present in metallic form are oxidised to the $\operatorname{Ir}(\mathrm{III})$ state which indicates the formation of $\operatorname{Ir}_{2} \mathrm{O}_{3}$. This is in complete agreement with the different behavior of cathodic dissolution peak 1 for the A-Ir and E-Ir analogues (Fig. 7a). Since more intensive dissolution is observed in the case of E-Ir, more $\mathrm{Ir}_{2} \mathrm{O}_{3}$ is expected to form in this sample than in A-Ir (which was not electrochemically pretreated). A survey of XANES data displayed in Table 1 shows that under different potentiostatic regimes the percentage of $\operatorname{Ir}(\mathrm{III})$ is generally increased. For example, after a potential hold at $0.9 \mathrm{~V}$ the E-Ir analogue contains about $20 \%$ of $\operatorname{Ir}(\mathrm{III})$ species. This is in-line with the assumed formation of $\mathrm{Ir}_{2} \mathrm{O}_{3}$ (Equation 3). Upon further increase of UPL the percentage of Ir(III) is slightly decreased with concomitant increase of the percentage of $\operatorname{Ir}(\mathrm{IV})$, as expected from the corresponding Nernst equations associated with Equations 4 and 5. An analogous experiment was performed for the $\mathrm{T}-\mathrm{IrO}_{2}$ sample; however no considerable changes in terms of relative compositions were detected (See Supporting Info, "Quasi in situ electrochemical XANES and EXAFS study"). As a whole, the XAS experiments reveal that under electrochemical conditions, $\mathrm{Ir}_{2} \mathrm{O}_{3}$ is the dominant oxide in the case of E-Ir, whereas rutile $\mathrm{IrO}_{2}$ is the prevailing oxide 
in the $\mathrm{T}-\mathrm{IrO}_{2}$ sample. This is in complete agreement with the main conclusion from the dissolution behaviour of the two analogues where the observed dissolution differences indicated that formation of $\mathrm{Ir}_{2} \mathrm{O}_{3}$ was most likely the reason for the altered dissolution mechanism; the latter, in turn, was triggered by a different OER mechanism taking place on the two analogues.

Table 1. Relative amounts (\%) of three Ir reference XANES spectra that describe the rest of Ir catalyst spectra at different electrochemical treatment by best linear combination fits. Uncertainty is \pm 1 .

\begin{tabular}{|c|c|c|c|}
\hline $\begin{array}{l}\text { Sample/Electrochemical } \\
\text { treatment }\end{array}$ & $\begin{array}{l}\text { Ir } \\
\text { metal }\end{array}$ & $\operatorname{Ir}\left(\mathbf{3 +}^{+}\right)$ & $\operatorname{Ir}(\mathbf{4 +})$ \\
\hline Ir/init (A-Ir) & 100 & 0 & 0 \\
\hline Ir/ 200 cycles (E-Ir) & 94 & 5 & 1 \\
\hline Ir $/ 0.9 \mathrm{~V}$ & 75 & 20 & 5 \\
\hline Ir $/ 1.2 \mathrm{~V}$ & 78 & 17 & 5 \\
\hline Ir $/ 1.6 \mathrm{~V}$ & 77 & 17 & 6 \\
\hline Ir $/ 0.05 \mathrm{~V}$ & 78 & 17 & 5 \\
\hline
\end{tabular}

Long term performance measurements In order to assess the trends in activity and stability, long term performance measurements were conducted in the thin-film RDE configuration setup. As expected, before the degradation treatment the OER activity of A-Ir is higher than that of $\mathrm{T}-\mathrm{IrO}_{2}$ (Fig. 10b) ${ }^{19,72}$. Interestingly, after 10000 degradation cycles $(1-1.6 \mathrm{~V})$ the former is still substantially more active than the latter. We note here that after electrochemical degradation the A-Ir sample transforms into the E-Ir analogue discussed in previous sections. However, for the sake of consistency the A-Ir notation is preserved in Fig. 12b.
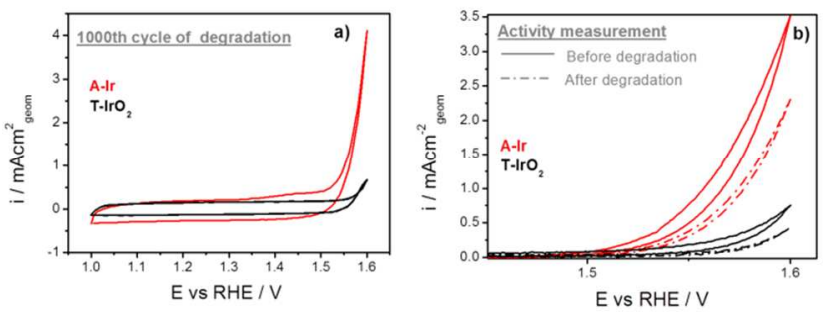

Figure 12. Rotating disc electrode measurements of A-Ir and T$\mathrm{IrO}_{2}$. a) $1000^{\text {th }}$ fast degradation cycle $\left(1 \mathrm{Vs}^{-1}, 1-1.6 \mathrm{~V}\right.$ vs RHE) and b) slow OER activity cycle $\left(10 \mathrm{mVs}^{-1}, 1-1.6 \mathrm{~V}\right.$ vs RHE) before and after degradation experiment.

The higher activity retention is in excellent agreement with the dissolution profiles in the OER region (Fig. 10d) where in the case of E-Ir dissolution peak 2 is inhibited. This confirms the non-inverse trend of activity-stability in the case of Ir materials ${ }^{21,22,53}$. Furthermore, a comparison of Tafel plots for T- $\mathrm{IrO}_{2}$ $(100 \mathrm{mV} / \mathrm{dec})$ and A-Ir $(67 \mathrm{mV} / \mathrm{dec})$ indicates that the rate determining step of OER is different for the two analogues as could be expected due to different surface structure as highlighted by XANES analysis (Table 1). The different OER mechanism should account for a different dissolution mechanism as well, as indeed noticed in Fig. 10d (and described in the Corrosion of thermally prepared $\mathrm{IrO}_{2}\left(\mathrm{~T}-\mathrm{IrO}_{2}\right)$ section. The Tafel slope has recently been justified as a descriptor for noble metal dissolution under OER conditions, where different Tafel slopes resulted in different stability of the metals ${ }^{48}$. In our case the different Tafel slopes should be ascribed to substantially different surface structure, namely the presence (E-Ir) or absence $\left(\mathrm{T}-\mathrm{IrO}_{2}\right)$ of $\mathrm{Ir}_{2} \mathrm{O}_{3}$.

CONCLUSION An approach consisting of a combination of a highly sensitive online electrochemical flow cell coupled to an inductively coupled plasma mass spectrometer, a thin-film rotating disc electrode, transmission and scanning electron microscopy and quasi in situ electrochemical XANES and EXAFS study was utilized for extensive electrochemical dissolution and stability studies of iridium and iridium oxide nanoparticles in order to obtain a comprehensive understanding of their electrochemical behavior. This approach enabled new insights into Ir corrosion behavior: (i) the dissolution process consists of anodic and cathodic counterparts, (ii) thermally prepared $\mathrm{IrO}_{2}$ exhibits the lowest activity and comparable stability, however still shows considerable anodic dissolution already at $0.9 \mathrm{~V}$ vs RHE, (iii) iridium nanoparticles show a higher OER activity even after a degradation protocol, (iv) at OER relevant potentials air- and thermally-oxidized iridium nanoparticles (A-Ir and $\mathrm{T}-\mathrm{IrO}_{2}$ ) dissolve predominantly through the formation of unstable $\operatorname{Ir}(>\mathrm{IV})$ and $(\mathrm{v})$ electrochemical oxidation (activation) of iridium nanoparticles changes the dissolution mechanism due to the formation of Ir(III) that induces a different dissolution pathway through its transient oxidation and reduction. We presume that the altered dissolution mechanism is also responsible for the altered OER mechanism. The dominant dissolution component in the case of as prepared and thermally prepared analogues is the formation of unstable $\operatorname{Ir}(>\mathrm{IV})$, which is absent in the case of electrochemically oxidized analogue. Here, the dissolution mechanism predominantly proceeds via transient formation of $\operatorname{Ir}(\mathrm{IV})$ to $\operatorname{Ir}(\mathrm{III})$.

\section{ASSOCIATED CONTENT}

\section{Supporting Information}

Transmission electron microscopy analysis, Identical location transmission microscopy (IL-TEM), Identical location scanning electron microscopy (IL-SEM), Electrochemical flow cell measurements, Quasi in situ electrochemical XANES and EXAFS study. This material is available free of charge via the Internet at http://pubs.acs.org.

\section{AUTHOR INFORMATION}

\section{Corresponding Authors}

*primoz.jovanovic@ki.si

*nejc.hodnik@ki.si

*miran.gaberscek@ki.si

\section{ACKNOWLEDGMENT}

Part of the work was carried out within the NATO Science for Peace Project EAP.SFPP 984925 - "DURAPEM". Project CALIPSOplus under the Grant Agreement 730872 from the EU Framework Programme for Research and Innovation 
HORIZON 2020 is acknowledged. Parts of this research were carried out at beamline P64 of PETRA III at DESY, Hamburg, a member of the Helmholtz Association (HGF) under project I-20160764 EC. We would like to thank Wolfgang Caliebe and Vadim Murzin for assistance during the experiment.

\section{REFERENCES}

(1) Payne, D. Nat. Chem. 2016, 8 (4), 392.

(2) Tilley, S. D.; Cornuz, M.; Sivula, K.; Grätzel, M. Angew. Chemie 2010, 122 (36), 6549-6552.

(3) Liu, D.-Q.; Yu, S.-H.; Son, S.-W.; Joo, S.-K. In ECS Transactions; ECS, 2008; Vol. 16, pp 103109.

(4) McCalla, E.; Abakumov, A. M.; Saubanère, M.; Foix, D.; Berg, E. J.; Rousse, G.; Doublet, M.-L.; Gonbeau, D.; Novák, P.; Van Tendeloo, G.; Dominko, R.; Tarascon, J.-M. Science 2015, 350 (6267), 1516-1521.

(5) Park, S.; Shao, Y.; Liu, J.; Wang, Y. Energy Environ. Sci. 2012, 5 (11), 9331.

(6) Antolini, E. ACS Catal. 2014, 4 (5), 1426-1440.

(7) Spöri, C.; Kwan, J. T. H.; Bonakdarpour, A.; Wilkinson, D. P.; Strasser, P. Angew. Chemie 2017, 129 (22), 6088-6117.

(8) Abu Irhayem, E.; Elzanowska, H.; Jhas, A. S.; Skrzynecka, B.; Birss, V. J. Electroanal. Chem. 2002, 538-539, 153-164.

(9) Cogan, S. F. Annu. Rev. Biomed. Eng. 2008, 10, 275-309.

(10) Cogan, S. F.; Guzelian, A. a; Agnew, W. F.; Yuen, T. G. H.; McCreery, D. B. J. Neurosci. Methods 2004, 137 (2), 141-150.

(11) Dau, H.; Limberg, C.; Reier, T.; Risch, M.; Roggan, S.; Strasser, P. ChemCatChem 2010, 2 (7), 724-761.

(12) Katsounaros, I.; Cherevko, S.; Zeradjanin, A. R.; Mayrhofer, K. J. J. Angew. Chem. Int. Ed. Engl. 2014, 53 (1), 102-121.

(13) Yagi, M.; Tomita, E.; Kuwabara, T. J. Electroanal. Chem. 2005, 579 (1), 83-88.

(14) Reier, T.; Oezaslan, M.; Strasser, P. ACS Catal. 2012, 2 (8), 1765-1772.
(15) Minguzzi, A.; Locatelli, C.; Lugaresi, O.; Achilli, E.; Cappelletti, G.; Scavini, M.; Coduri, M.; Masala, P.; Sacchi, B.; Vertova, A.; Ghigna, P.; Rondinini, S. ACS Catal. 2015, 5 (9), 5104-5115.

(16) Danilovic, N.; Subbaraman, R.; Chang, K. C.; Chang, S. H.; Kang, Y.; Snyder, J.; Paulikas, A. P.; Strmcnik, D.; Kim, Y. T.; Myers, D.; Stamenkovic, V. R.; Markovic, N. M. Angew. Chem. Int. Ed. Engl. 2014, 53 (51), 14016-14021.

Man, I. C.; Su, H.-Y.; Calle-Vallejo, F.; Hansen, H. a.; Martínez, J. I.; Inoglu, N. G.; Kitchin, J.; Jaramillo, T. F.; Nørskov, J. K.; Rossmeisl, J. ChemCatChem 2011, 3 (7), 1159-1165.

Atanasoski, R. T.; Atanasoska, L. L.; Cullen, D. a.; Haugen, G. M.; More, K. L.; Vernstrom, G. D. Electrocatalysis 2012, 3 (3-4), 284-297.

Danilovic, N.; Subbaraman, R.; Chang, K.-C.; Chang, S. H.; Kang, Y. J.; Snyder, J.; Paulikas, A. P.; Strmcnik, D.; Kim, Y.; Myers, D.; Stamenkovic, V. R.; Markovic, N. M. J. Phys. Chem. Lett. 2014, 5 (14), 2474-2478.

Pfeifer, V.; Jones, T. E.; Wrabetz, S.; Massué, C.; Velasco Vélez, J. J.; Arrigo, R.; Scherzer, M.; Piccinin, S.; Hävecker, M.; Knop-Gericke, A.; Schlögl, R. Chem. Sci. 2016, 7 (11), 6791-6795.

(21) Reier, T.; Pawolek, Z.; Cherevko, S.; Bruns, M.; Jones, T.; Teschner, D.; Selve, S.; Bergmann, A.; Nong, H. N.; Schlögl, R.; Mayrhofer, K. J. J.; Strasser, P. J. Am. Chem. Soc. 2015, 137 (40), 13031-13040.

(22) Cherevko, S.; Reier, T.; Zeradjanin, A. R.; Pawolek, Z.; Strasser, P.; Mayrhofer, K. J. J. Electrochem. commun. 2014, 48, 81-85.

Forgie, R.; Bugosh, G.; Neyerlin, K. C.; Liu, Z.; Strasser, P. Electrochem. Solid-State Lett. 2010, 13 (4), B36.

(24) Neyerlin, K. C.; Bugosh, G.; Forgie, R.; Liu, Z.; Strasser, P. J. Electrochem. Soc. 2009, 156 (3), B363.

Lee, K.; Zhang, L.; Zhang, J. J. Power Sources 2007, 170 (2), 291-296.

Nong, H. N.; Gan, L.; Willinger, E.; Teschner, D.; Strasser, P. Chem. Sci. 2014, 5 (8), 2955.

Nong, H. N.; Oh, H.-S.; Reier, T.; Willinger, E.; Willinger, M.-G.; Petkov, V.; Teschner, D.; 
Strasser, P. Angew. Chem. Int. Ed. Engl. 2015, 54 (10), 2975-2979.

(28) Strasser, P.; Koh, S.; Anniyev, T.; Greeley, J.; More, K.; Yu, C.; Liu, Z.; Kaya, S.; Nordlund, D.; Ogasawara, H.; Toney, M. F.; Nilsson, A. Nat. Chem. 2010, 2, 454-460.

(29) Jia, Q.; Caldwell, K.; Strickland, K.; Ziegelbauer, J. M.; Liu, Z.; Yu, Z.; Ramaker, D. E.; Mukerjee, S. 2015, No. 111.

(30) Oh, H.-S.; Nong, H. N.; Reier, T.; Gliech, M.; Strasser, P. Chem. Sci. 2015, 6 (6), 3321-3328.

(31) Zhao, C.; Yu, H.; Li, Y.; Li, X.; Ding, L.; Fan, L. J. Electroanal. Chem. 2013, 688, 269-274.

(32) Alia, S. M.; Pylypenko, S.; Neyerlin, K. C.; Kocha, S. S.; Pivovar, B. S. ECS Trans. 2015, 69 (17), 883-892.

(33) Hodnik, N.; Baldizzone, C.; Polymeros, G.; Geiger, S.; Grote, J.-P.; Cherevko, S.; Mingers, A.; Zeradjanin, A.; Mayrhofer, K. J. J. Nat. Commun. 2016, 7 (October), 13164.

(34) Hodnik, N.; Jovanovič, P.; Pavlišič, A.; Jozinović, B.; Zorko, M.; Bele, M.; Šelih, V. S.; Šala, M.; Hočevar, S.; Gaberšček, M. J. Phys. Chem. C 2015, 119 (18), 10140-10147.

(35) Jovanovič, P.; Šelih, V. S.; Šala, M.; Hočevar, S.; Ruiz-Zepeda, F.; Hodnik, N.; Bele, M.; Gaberšček, M. Electrochim. Acta 2016, 211, 851-859.

(36) Gatalo, M.; Jovanovič, P.; Polymeros, G.; Grote, J.P.; Pavlišič, A.; Ruiz- Zepeda, F.; Šelih, V. S.; Šala, M.; Hočevar, S.; Bele, M.; Mayrhofer, K. J. J.; Hodnik, N.; Gaberšček, M. ACS Catal. 2016, 6 (3), 1630-1634.

(37) Jovanovič, P.; Šelih, V. S.; Šala, M.; Hočevar, S. B.; Pavlišič, A.; Gatalo, M.; Bele, M.; RuizZepeda, F.; Čekada, M.; Hodnik, N.; Gaberšček, M. J. Power Sources 2016, 327, 675-680.

(38) Jovanovič, P.; Pavlišič, A.; Šelih, V. S.; Šala, M.; Hodnik, N.; Bele, M.; Hočevar, S.; Gaberšček, M. ChemCatChem 2014, 6, 449-453.

(39) Pavlišič, A.; Jovanovič, P.; Šelih, V. S.; Šala, M.; Hodnik, N.; Hočevar, S.; Gaberšček, M. Chem. Commun. (Camb). 2014, 50 (28), 3732-3734.
(40) Hodnik, N.; Zorko, M.; Jozinović, B.; Bele, M.; Dražič, G.; Hočevar, S.; Gaberšček, M. Electrochem. commun. 2013, 30, 75-78.

(41) Zorko, M.; Jozinović, B.; Bele, M.; Hodnik, N.; Gaberšček, M. Ultramicroscopy 2014, 140, 44-50.

(42) Hodnik, N.; Zorko, M.; Bele, M.; Hočevar, S.; Gaberšček, M.; Hoc, S.; Gabers, M. J. Phys. Chem. C 2012, 116, 21326-21333.

(43) Hodnik, N.; Dehm, G.; Mayrhofer, K. J. J. Acc. Chem. Res. 2016, 49 (9), 2015-2022.

(44) Cherevko, S. J. Electroanal. Chem. 2017, 787, 1113.

(45) Pickup, P. G.; Birss, V. I. J. Electroanal. Chem. Interfacial Electrochem. 1987, 220 (1), 83-100.

(46) Abbott, D. F.; Lebedev, D.; Waltar, K.; Povia, M.; Nachtegaal, M.; Fabbri, E.; Copéret, C.; Schmidt, T. J. Chem. Mater. 2016, 28 (18), 6591-6604.

Pourbaix, M. Atlas of Electrochemical Equilibria in Aqueous Solutions; Pergamon: Oxford, 1966.

Cherevko, S.; Zeradjanin, A. R.; Topalov, A. A.; Kulyk, N.; Katsounaros, I.; Mayrhofer, K. J. J. ChemCatChem 2014, 6 (8), 2219-2223.

Topalov, A. A.; Katsounaros, I.; Auinger, M.; Cherevko, S.; Meier, J. C.; Klemm, S. O.; Mayrhofer, K. J. J. Angew. Chem. Int. Ed. Engl. 2012, 51 (50), 12613-12615.

(50) Cherevko, S.; Zeradjanin, a. R.; Keeley, G. P.; Mayrhofer, K. J. J. J. Electrochem. Soc. 2014, 161 (12), H822-H830.

(51) Cherevko, S.; Topalov, A. a.; Zeradjanin, A. R.; Katsounaros, I.; Mayrhofer, K. J. J. RSC Adv. 2013, 3 (37), 16516.

(52) Fierro, S.; Nagel, T.; Baltruschat, H.; Comninellis, C. Electrochem. commun. 2007, 9 (8), 1969-1974.

(53) Cherevko, S.; Geiger, S.; Kasian, O.; Kulyk, N.; Grote, J.-P.; Savan, A.; Shrestha, B. R.; Merzlikin, S.; Breitbach, B.; Ludwig, A.; Mayrhofer, K. J. J. Catal. Today 2016, 262, 170-180.
Cherevko, S.; Geiger, S.; Kasian, O.; Mingers, A.; Mayrhofer, K. J. J. J. Electroanal. Chem. 2016, 773, 69-78. 
(55) Cherevko, S.; Geiger, S.; Kasian, O.; Mingers, A.; Mayrhofer, K. J. J. J. Electroanal. Chem. 2016, 774, 102-110.

(56) Rossmeisl, J.; Qu, Z.-W.; Zhu, H.; Kroes, G.-J.; Nørskov, J. K. J. Electroanal. Chem. 2007, 607 (12), 83-89.

(57) Minguzzi, A.; Lugaresi, O.; Locatelli, C.; Rondinini, S.; D’Acapito, F.; Achilli, E.; Ghigna, P. Anal. Chem. 2013, 85 (15), 7009-7013.

(58) Reier, T.; Teschner, D.; Lunkenbein, T.; Bergmann, a.; Selve, S.; Kraehnert, R.; Schlogl, R.; Strasser, P. J. Electrochem. Soc. 2014, 161 (9), F876-F882.

(59) Pfeifer, V.; Jones, T. E.; Velasco Vélez, J. J.; Arrigo, R.; Piccinin, S.; Hävecker, M.; KnopGericke, A.; Schlögl, R. Chem. Sci. 2017, 8 (3), 2143-2149.

(60) Pfeifer, V.; Jones, T. E.; Velasco Vélez, J. J.; Massué, C.; Arrigo, R.; Teschner, D.; Girgsdies, F.; Scherzer, M.; Greiner, M. T.; Allan, J.; Hashagen, M.; Weinberg, G.; Piccinin, S.; Hävecker, M.; Knop-Gericke, A.; Schlögl, R. Surf. Interface Anal. 2016, 48 (5), 261-273.

(61) Pfeifer, V.; Jones, T. E.; Velasco Vélez, J. J.; Massué, C.; Greiner, M. T.; Arrigo, R.; Teschner, D.; Girgsdies, F.; Scherzer, M.; Allan, J.; Hashagen, M.; Weinberg, G.; Piccinin, S.; Hävecker, M.; Knop-Gericke, A.; Schlögl, R. Phys. Chem. Chem. Phys. 2016, 18 (4), 2292-2296.

(62) Kötz, R. J. Electrochem. Soc. 1984, 131 (1), 72.

(63) Blakemore, J. D.; Schley, N. D.; Balcells, D.; Hull, J. F.; Olack, G. W.; Incarvito, C. D.; Eisenstein, O.; Brudvig, G. W.; Crabtree, R. H. J. Am. Chem. Soc. 2010, 132 (45), 16017-16029.
(64) Trasatti, S. Electrochim. Acta 1984, 29 (11), 1503 1512.

(65) Sanchez Casalongue, H. G.; Ng, M. L.; Kaya, S.; Friebel, D.; Ogasawara, H.; Nilsson, A. Angew. Chem. Int. Ed. Engl. 2014, 53 (28), 7169-7172.

(66) Burke, L. D.; O’Sullivan, E. J. M. J. Electroanal. Chem. Interfacial Electrochem. 1981, 117 (1), 155160.

(67) Hodnik, N.; Jeyabharathi, C.; Meier, J. C.; Kostka, A.; Phani, K. L.; Rečnik, A.; Bele, M.; Hočevar, S.; Gaberšček, M.; Mayrhofer, K. J. J. Phys. Chem. Chem. Phys. 2014, 16, 13610-13615.

(68) Minguzzi, A.; Lugaresi, O.; Achilli, E.; Locatelli, C.; Vertova, A.; Ghigna, P.; Rondinini, S. Chem. Sci. 2014, 5 (9), 3591.

(69) Chang, S. H.; Danilovic, N.; Chang, K.-C.; Subbaraman, R.; Paulikas, A. P.; Fong, D. D.; Highland, M. J.; Baldo, P. M.; Stamenkovic, V. R.; Freeland, J. W.; Eastman, J. a; Markovic, N. M. Nat. Commun. 2014, 5 (May), 4191.

(70) Rao, M. L. B.; Damjanovic, A.; Bockris, J. O. J. Phys. Chem. 1963, 67 (11), 2508-2509.

(71) Topalov, A. A.; Cherevko, S.; Zeradjanin, A. R.; Meier, J. C.; Katsounaros, I.; Mayrhofer, K. J. J. Chem. Sci. 2014, 5, 631-638.

(72) Paoli, E. A.; Masini, F.; Frydendal, R.; Deiana, D.; Schlaup, C.; Malizia, M.; Hansen, T. W.; Horch, S.; Stephens, I. E. L.; Chorkendorff, I. Chem. Sci. 2015, 6 (1), 190-196. 
Table of Contents

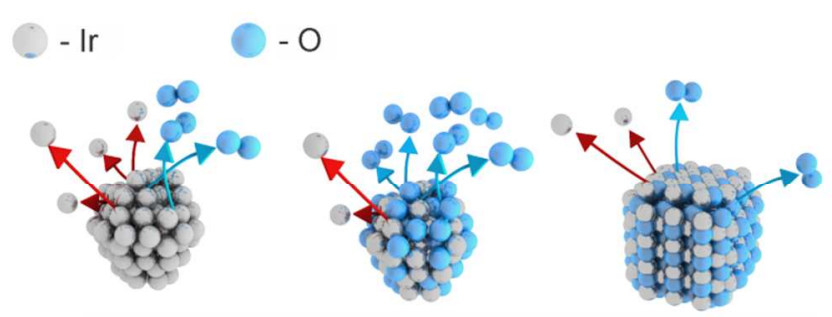

Metallic Ir El. Amorph. Ir-Oxide Rutile Ir-Oxide

14

15

16

17

18

19

20

21

22

23

24

25

26

27

28

29

30

31

32

33

34

35

36

37

38

39

40

41

42

43

44

45

46

47

48

49

50

51

52

53

54

55

56

57

58

59

60 